\title{
Modelo do estudante baseado em emoções e perfis de personalidade para recomendação de estratégias pedagógicas personalizadas
}

\author{
Sara L. de Melo ${ }^{1}$, Adilmar C. Dantas ${ }^{2}$, Márcia A. Fernandes ${ }^{2}$ \\ ${ }^{1}$ Departamento de Engenharia Elétrica \\ ${ }^{2}$ Departamento de Ciência da Computação \\ Universidade Federal de Uberlândia \\ Uberlândia - Minas Gerais - Brasil \\ E-mail: saraluziamelo@gmail.com, adilmar@ufu.br, marcia@ufu.br
}

\begin{abstract}
This paper proposes a student model based on emotions and personality profiles in order to develop the affective profile of the student in a Virtual Learning Environments. With the information contained in the student model will be selected pedagogical strategies appropriate to each profile. For the validation of this approach, techniques of Artificial Neural Networks and Decision Tree were used. The analysis have as a result an overall accuracy $97.28 \%$ in the classification of the nine personality profiles, as well as the validation of the set of pedagogical strategies. Thus, by detecting an harmful emotion to the learning, the student will receive personalized stimuli of their characteristics and, consequently, the approximation of the emotion that promotes learning.
\end{abstract}

Resumo. Este trabalho propõe um modelo do estudante baseado em emoções e perfis de personalidade com intuito de desenvolver o perfil afetivo do estudante em Ambientes Virtuais de Aprendizagem. Através das informações contidas no modelo do estudante serão selecionadas as estratégias pedagógicas adequadas a cada perfil. Para validação desta proposta utilizou-se as técnicas de Redes Neurais Artificiais e Árvore de Decisão. Por meio de uma análise experimental, têm-se como resultados uma precisão geral de 97,28\% na classificação dos nove perfis de personalidade, bem como a validação do conjunto ótimo de estratégias pedagógicas. Assim, ao detectar uma emoção prejudicial ao aprendizado o estudante receberá estímulos personalizados as suas características e, consequentemente, a aproximação da emoção que promova à aprendizagem.

\section{Introdução}

As emoções interferem diretamente no processo de aprendizagem. Estudantes que se encontram em uma emoção prejudicial ao aprendizado não conseguem assimilar da melhor maneira possível o conteúdo que lhe é proposto. Nesta perspectiva, as pesquisas de [Izard 1984] afirmam que emoções negativas induzidas no estudante prejudicam o seu desempenho em tarefas cognitivas, assim como as emoções positivas possuem um efeito contrário [Jaques and Vicari 2005].

As seis emoções básicas expressas pelos seres humanos são denominadas de emoções primárias e foram classificadas por: alegria, tristeza, surpresa, medo, desprezo e raiva. No âmbito acadêmico, essas emoções foram divididas em duas classes: emoções 
VI Congresso Brasileiro de Informática na Educação (CBIE 2017)

Anais do XXVIII Simpósio Brasileiro de Informática na Educação (SBIE 2017)

positivas ao aprendizado e emoções negativas ao aprendizado. Dentre essas seis emoções, apenas a emoção alegria é considerada como um estado afetivo ideal ao aprendizado. Sendo as outras cinco emoções, exceto em certas circunstâncias a emoção surpresa, são emoções consideradas negativas à aprendizagem, responsáveis por inferir comportamentos pouco favoráveis no processo de ensino e aprendizado [Chabot 2005].

Similarmente as emoções, a motivação oferecida ao estudante também é um fator fundamental para o sucesso na aprendizagem [Stipek 2002]. No entanto, a utilização da mesma estratégia pedagógica não produz efeito satisfatório para todos os estudantes. Uma vez que, o modo de perceber os estímulos do ambiente ao redor e de reagir a ele, difere consideravelmente de um indivíduo para o outro. Nem todos possuem o mesmo sentimento diante das situações ou respostas aos estímulos experimentados [Giraffa and Viccari 1999], [Chabot 2005].

A Computação Afetiva aplicada à educação utiliza essencialmente a extração dos aspectos relacionados com a afetividade, tais como emoções e personalidade, com intuito de fornecer ao estudante um ambiente de aprendizagem mais afetivo. Sistema Tutor Inteligente (STI), em sua arquitetura clássica, é composto por três módulos denominados de Modelo Pedagógico, Modelo do Estudante e Modelo de Domínio. Contudo, para [Chrysafiadi and Virvou 2015] o Modelo do Estudante é o principal módulo da arquitetura de um STI, pois é através dele que define como o sistema toma decisões, em momentos apropriados, que promovem apoio e/ou instruções personalizadas ao estudante.

Para a construção de um ambiente propício à aprendizagem devem ser integrados a arquitetura do sistema informações referentes aos aspectos emocionais, pedagógicos e motivacionais [Rodrigues and Carvalho 2005]. Neste contexto, com o objetivo de observar as emoções do estudante e utilizá-las de maneira efetiva no processo de ensino e aprendizado, este trabalho propõe um Modelo de Estudante e um Módulo Pedagógico, amparados pedagogicamente pela teoria perfis de personalidade [Chabot 2005]. Esta teoria correlaciona características sobre personalidade e emoções, com ênfase na aprendizagem, tendo como base o modelo psicobiológico de personalidade de [Cloninger et al. 1993]. Além disso, são apresentados os resultados computacionais obtidos para verificar o bom funcionamento e aplicabilidade da abordagem proposta.

Este artigo está organizado da seguinte maneira: na Seção 2 é apresentada a teoria que ampara a modelagem proposta; na Seção 3 são apresentados os principais trabalhos correlatos; na Seção 4 é detalhado o modelo do estudante; na Seção 5 são exibidos os resultados experimentais das técnicas de Inteligência Artificial utilizadas, bem como resultados com estudantes reais e, por fim, na Seção 6 são apresentados as considerações finais e trabalhos futuros.

\section{Teoria Perfis de Personalidade}

O campo da personalidade refere-se as particularidades e diferenças do indivíduo. Na literatura, existem várias teorias que abordam a definição da personalidade e seus aspectos. Dentre elas, a teoria Big Five Factors [John and Srivastava 1999], identificam cinco traços de personalidade. O modelo de Myers-Briggs Type Indicator [Myers et al. 1985], permite identificar dezesseis traços de personalidade. O modelo psicobiológico de [Cloninger et al. 1993] que divide o campo personalidade em duas dimensões: A dimensão inata (temperamento) e a dimensão adquirida (caráter). Por meio do modelo 
VI Congresso Brasileiro de Informática na Educação (CBIE 2017)

Anais do XXVIII Simpósio Brasileiro de Informática na Educação (SBIE 2017)

de [Cloninger et al. 1993], [Chabot 2005] apresenta a teoria perfis de personalidade.

Na teoria perfis de personalidade [Chabot 2005], são exibidas três dimensões psicológicas: 1) A busca do Novo (BN); 2) Evitamento da punição e dor (EPD); 3) Necessidade de Recompensa e Afeto (NRA). Em cada uma dessas dimensões são detalhadas características que definem o temperamento do indivíduo, com ênfase na aprendizagem. Além disso, cada dimensão pode receber um valor que representa determinado nível (alto, médio e baixo). Cada nível atribuído à dimensão possibilita identificar características psicológicas do estudante. Desse modo, a combinação dos níveis atribuídos às três dimensões psicológicas resultam em nove perfis de personalidade de [Chabot 2005] mostrados na Tabela 1.

Tabela 1. Os nove perfis de personalidade, dimensões e níveis
\begin{tabular}{l|l|l|l}
\hline Perfis de Personalidade & \multicolumn{1}{c}{ BN } & \multicolumn{1}{c}{ EPD } & NRA \\
\hline Temerário & Alto & Baixo & Baixo \\
\hline Teatral & Alto & Baixo & Alto \\
\hline Excessivo & Alto & Alto & Baixo \\
\hline Astucioso & Alto & Alto & Alto \\
\hline Meticuloso & Baixo & Alto & Baixo \\
\hline Afetivo & Baixo & Baixo & Alto \\
\hline Dócil & Baixo & Alto & Alto \\
\hline Eremita & Baixo & Baixo & Baixo \\
\hline Flexível & Médio & Médio & Médio \\
\hline
\end{tabular}

Analisando a Tabela 1, note que, um estudante é considerado com o perfil Temerário se, e somente se, o agrupamento dos níveis BN, EPD e NRA forem atribuídos às dimensões com os valores alto, baixo e baixo, respectivamente. Há uma variedade de informações, descritas por [Chabot 2005], que caracterizam os níveis alto e baixo. Sendo assim, efetuar a classificação dos perfis de personalidade apenas pelo comportamento observável torna-se uma tarefa não trivial devido à complexidade de informações a serem observadas/medidas e, em seguida, agrupadas.

\section{Trabalhos Relacionados}

O primeiro trabalho que conceitua o impacto das emoções sobre à aprendizagem foi proposto por [Kort et al. 2001]. Nesta abordagem foi desenvolvido um modelo de construção de aprendizagem em quatro quadrantes emocionais dividindo as emoções básicas em duas classes: emoções positivas (encontram-se à direita) e emoções negativas (encontram-se à esquerda). As emoções positivas estão relacionadas ao prazer e ao aprendizado. O estudante que encontra-se em uma emoção negativa deverá girar na espiral em sentido ao eixo da direita e do topo da espiral. Porém, não foram propostas ações pedagógicas responsáveis pela evolução do estudante na espiral de aprendizagem.

Em [Frozza et al. 2011], foi proposto um modelo para estimular estudantes através da atuação de dois agentes pedagógicos animados, denominados agente Dóris e agente Dimi. Através das emoções dos estudantes, os dois agentes são integrados no ambiente virtual de aprendizagem, a fim de interagir com estudantes de acordo com suas emoções e o comportamento observável. O agente tutor Dóris tem papel semelhante a 
de um professor, identificando as características de aprendizagem do estudante. O agente companheiro Dimi atua juntamente com o estudante na realização de atividades propostas pelo ambiente virtual, fornecendo dicas e desafios.

[Chen and Lee 2012] propuseram um método afetivo de ensino para detectar a emoção do estudante usando mapa emocional. Ao verificar que o estudante encontra-se fora do estado emocional positivo, o modelo inicializa um módulo de gestão de controle de emoções até o estudante entrar num estado favorável à aprendizagem. Quando o estudante estiver localizado na área da emoção positiva ao aprendizado apresentam-se as instruções de um determinado conteúdo e verifica, novamente, o estado afetivo do estudante. Caso contrário, o estudante é submetido a prática de testes finais de cada lição.

Dentre os trabalhos supracitados é possível perceber que as emoções representam um fator importante no processo de ensino e aprendizagem. Porém, nas abordagens que integram aspectos motivacionais, ao detectar uma emoção desfavorável ao aprendizado os estímulos aplicados ao estudante não são feitos de maneira individualizada. Considerando que cada indivíduo reage de forma diferente a determinada ação, é proposto neste trabalho a personalização dos estímulos/motivação oferecidos ao estudante em função de seu perfil de personalidade.

\section{Modelo do estudante baseado em emoções e perfis de personalidade}

O Modelo do Estudante (ME) exposto neste trabalho, denominado de Emotion- $P$, baseiase da hipótese de que as emoções interferem diretamente no processo cognitivo. Assim, o ME tem como principal objetivo realizar o registro e o conhecimento das características emocionais e individuais do estudante relacionadas com seu perfil de personalidade. Posteriormente, será feita a seleção das estratégias pedagógicas, Módulo Pedagógico (MP), bem como um conjunto de regras que traduzem as estratégias pedagógicas adequadas ao estudante.

As etapas a serem realizadas para a validação computacional dos aspectos teóricos que amparam o modelo proposto e a arquitetura geral do Emotion-P são apresentados na Figura 1.

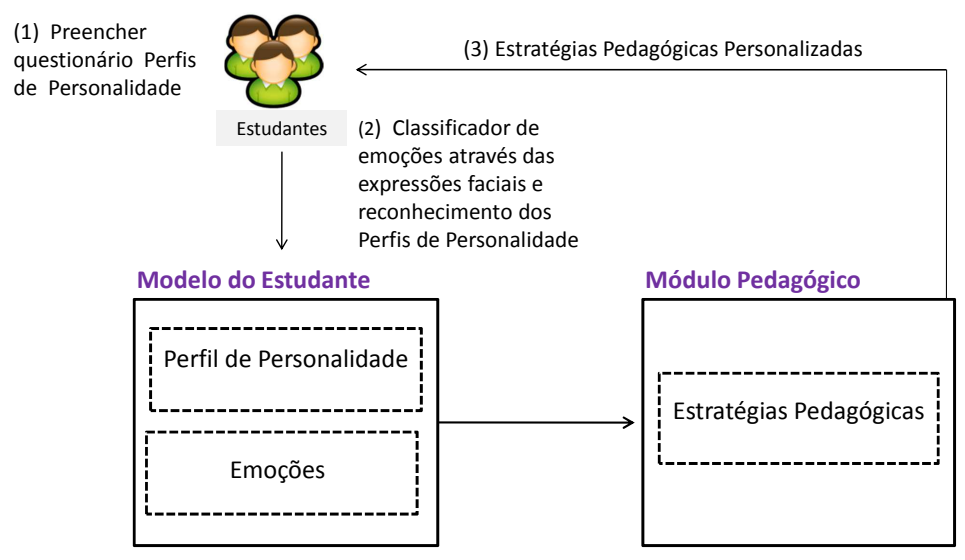

Figura 1. Visão Geral do Modelo do Estudante Emotion-P.

Ao observar a modelagem na Figura 1, a primeira entrada do ME é o perfil de personalidade do estudante. Para efetuar o reconhecimento e agrupamento das informações 
VI Congresso Brasileiro de Informática na Educação (CBIE 2017)

Anais do XXVIII Simpósio Brasileiro de Informática na Educação (SBIE 2017)

presentes na teoria de [Chabot 2005], o estudante responderá um questionário de múltipla escolha uma única vez. É importante salientar que, a teoria perfis de personalidade não apresenta uma maneira automática para classificação de cada perfil, dimensões, níveis e suas combinações. Além disso, [Chabot 2005] não apresentou nenhum questionário, apenas definiu características predominantes de cada perfil nas três dimensões psicológicas e em dois níveis, dentre os três níveis definidos.

Para isto, julgou-se necessário a elaboração de um questionário. O questionário é composto por 62 afirmativas, pode ser visto em [Melo 2016], de acordo com as características resumidas apontadas por [Chabot 2005]. As questões foram divididas da seguinte maneira: 18 afirmativas relacionadas aos níveis da dimensão $\mathrm{BN}, 22$ afirmativas que caracterizam níveis da dimensão EPD e outras 22 para extrair informações que representam os níveis da dimensão NRA. Sendo assim, as respostas ao questionário serão utilizadas como entrada para uma Rede Neural Artificial (detalhada na Seção 5) com intuito de classificar de maneira significativa todos perfis de personalidade.

Um outra entrada do ME são as emoções básicas do estudante. As emoções do estudante serão observadas durante todo o processo de ensino e aprendizado. Nesta modelagem o estado afetivo ideal para à aprendizagem é a emoção "alegria". Assim, para a classificação das emoções utilizou-se um sistema em tempo real para o reconhecimento automático das emoções, através das expressões faciais, sendo detalhado em [Dantas et al. 2015]. Como resultados têm-se uma precisão superior a 90\% na classificação dinâmica das seis emoções.

Por meio dessa modelagem, mostrada na Figura 1, ao detectar uma emoção prejudicial à aprendizagem num determinado módulo do curso, o MP receberá informações de acordo com as características individuais e emocionais de cada estudante. Desse modo, serão integrados ao ambiente de ensino aspectos emocionais, pscicológicos e, além disso, a personalização dos aspectos motivacionais responsáveis por conduzir e/ou aproximar o estudante da emoção que estimule suas habilidades de aprendizagem.

\section{Experimentos Realizados}

A validação computacional do Emotion- $P$ centra-se na execução de duas principais tarefas, classificação dos perfis de personalidade e a determinação das estratégias pedagógicas. A seguir são apresentados as técnicas computacionais integradas ao ME e MP, bem como os resultados obtidos da análise experimental para cada módulo. Além disso, são apresentados os resultados obtidos com estudantes reais.

\subsection{Classificação Perfis de Personalidade utilizando Redes Neurais Artificiais}

Numa Rede Neural Artificial (RNA) do tipo Perceptron Múltiplas Camadas, basicamente, existem três camadas (entrada, intermediária e saída), sendo que na camada intermediária podem existir outras camadas, dependendo da demanda do problema a ser solucionado/otimizado. Neste trabalho, a classificação dos nove perfis de personalidade é realizada com esse tipo de RNA utilizando o algoritmo de aprendizado backpropagation [Fausett 1994].

Para o processo de treinamento da RNA, desenvolveu-se três bases de treinamento constituídas por diferentes possíveis respostas aleatórias ao questinário, que representam determinado perfil de personalidade. Com intuito de definir a base de treinamento 
VI Congresso Brasileiro de Informática na Educação (CBIE 2017)

Anais do XXVIII Simpósio Brasileiro de Informática na Educação (SBIE 2017)

e a arquitetura de RNA ótimos, realizou-se um análise experimental com 4 arquiteturas de RNA, sendo uma camada de entrada composta por 62 neurônios (respostas ao questionário), camada de saída com 9 neurônios (perfis de personalidade), alterando somente o número de camadas ocultas e seus tamanhos. A Tabela 2 exibe os resultados da classificação dos perfis de personalidade para cada arquitetura de RNA, obtidos por meio da base de treinamento composta por 1.000 amostras.

Tabela 2. Resultados da classificação dos perfis de personalidade com 1.000 amostras para treinamento e 4 arquiteturas de RNA

\begin{tabular}{lccccc}
\hline \multicolumn{1}{c}{ Perfis } & $n$ & $\begin{array}{c}\text { 1 camada oculta } \\
\text { com 5 neurônios }\end{array}$ & $\begin{array}{c}\text { 1 camada oculta } \\
\text { com 20 neurônios }\end{array}$ & $\begin{array}{c}\text { 2 camadas ocultas } \\
\text { com 5 neurônios }\end{array}$ & $\begin{array}{c}2 \text { camadas ocultas } \\
\text { com 20 neurônios }\end{array}$ \\
\hline Afetivo & 115 & $86.09 \%$ & $79.13 \%$ & $86.09 \%$ & $84.35 \%$ \\
\hline Astucioso & 100 & $86 \%$ & $76 \%$ & $75 \%$ & $81 \%$ \\
\hline Dócil & 107 & $88.79 \%$ & $85.98 \%$ & $82.24 \%$ & $85.05 \%$ \\
\hline Eremita & 106 & $81.13 \%$ & $82.08 \%$ & $83.96 \%$ & $83.96 \%$ \\
\hline Excessivo & 106 & $84.91 \%$ & $83.02 \%$ & $80.19 \%$ & $79.25 \%$ \\
\hline Flexível & 117 & $35.04 \%$ & $20.51 \%$ & $29.06 \%$ & $42.74 \%$ \\
\hline Meticuloso & 103 & $85.44 \%$ & $87.38 \%$ & $76.70 \%$ & $84.47 \%$ \\
\hline Teatral & 119 & $93.28 \%$ & $89.92 \%$ & $83.19 \%$ & $85.71 \%$ \\
\hline Temerário & 127 & $82.68 \%$ & $81.10 \%$ & $83.46 \%$ & $81.10 \%$ \\
\hline \multicolumn{7}{c}{ Total } & $\mathbf{1 . 0 0 0}$ & $\mathbf{8 0 . 1 0 \%}$ & $\mathbf{7 5 . 8 0 \%}$ & $\mathbf{7 5 . 4 0 \%}$ & $\mathbf{7 8 . 4 0 \%}$ \\
\hline \multicolumn{7}{r}{ Média } & 80.37 & 76.12 & 75.54 & 78.62 \\
\hline Mínimo & 35.04 & 20.51 & 29.06 & 42.74 \\
\hline Méximo & 93.28 & 89.92 & 86.09 & 85.71 \\
\hline
\end{tabular}

onde, $n$ é a quantidade de amostra que representa determinado perfil de personalidade.

Ao observar a Tabela 2, a classificação geral dos perfis, automática por meio da RNA após as respostas ao questionário, em nenhuma arquitetura obteve uma classificação significativa ( $>90 \%$ ). A arquiteura composta por 1 camada oculta com 5 neurônios apresentou maior precisão $(80,10 \%)$ no reconhecimento geral dos nove perfis.

Observando a classificação para cada perfil, o único perfil que obteve precisão superior a $90 \%$ foi o perfil "Teatral", por meio da arquitetura composta por 1 camada oculta com 5 neurônios. No entanto, a arquitetura definida por 2 camadas ocultas com 20 neurônios em cada, tem uma melhor precisão, levando em consideração o desvio padrão. Assim, a base de treinamento oferecida à RNA deverá ser maior que 1.000 amostras.

A Tabela 3, exibe os resultados experimentais obtidos com uma base de treinamento composta com 5.000 amostras e as mesmas arquiteturas neurais simuladas anteriormente. Ao observar a Tabela 3, note que, atingiu uma taxa de precisão geral superior a 90\% para as três primeiras definições de arquitetura neural. No entanto, o perfil "Flexível" obteve um acurácia de 76,63\%,85,98\%, 78,13\% e 75,46\%, para as quatro arquiteturas de RNA, respectivamente.

Contudo, ainda na Tabela 3, a quantidade de amostras que representam o perfil "Flexível" (nível médio em todas as dimensões) é superior comparado as amostras (exemplos) que representam os demais perfis de personalidade no conjunto de treinamento. Objetivando uma precisão significativa para todos os perfis de personalidade, são detalhados na Tabela 4 os resultados obtidos por meio do conjunto de treinamento composto por 10.000 amostras. 
VI Congresso Brasileiro de Informática na Educação (CBIE 2017)

Anais do XXVIII Simpósio Brasileiro de Informática na Educação (SBIE 2017)

Tabela 3. Resultados da classificação dos perfis de personalidade com 5.000 amostras para treinamento e 4 arquiteturas de RNA

\begin{tabular}{lccccc}
\hline \multicolumn{1}{c}{ Perfis } & $n$ & $\begin{array}{c}\text { 1 camada oculta } \\
\text { com 5 neurônios }\end{array}$ & $\begin{array}{c}\text { 1 camada oculta } \\
\text { com 20 neurônios }\end{array}$ & $\begin{array}{c}\text { 2 camadas ocultas } \\
\text { com 5 neurônios }\end{array}$ & $\begin{array}{c}\text { 2 camadas ocultas } \\
\text { com 20 neurônios }\end{array}$ \\
\hline Afetivo & 555 & $97.30 \%$ & $94.41 \%$ & $96.04 \%$ & $89.19 \%$ \\
\hline Astucioso & 505 & $96.83 \%$ & $94.85 \%$ & $95.25 \%$ & $91.09 \%$ \\
\hline Dócil & 554 & $97.83 \%$ & $96.39 \%$ & $96.21 \%$ & $93.14 \%$ \\
\hline Eremita & 550 & $96.36 \%$ & $96 \%$ & $96.55 \%$ & $92.18 \%$ \\
\hline Excessivo & 555 & $95.68 \%$ & $95.86 \%$ & $95.50 \%$ & $89.19 \%$ \\
\hline Flexível & 599 & $76.63 \%$ & $85.98 \%$ & $78.13 \%$ & $75.46 \%$ \\
\hline Meticuloso & 562 & $96.80 \%$ & $95.55 \%$ & $96.26 \%$ & $93 \%$ \\
\hline Teatral & 569 & $96.31 \%$ & $96.13 \%$ & $95.78 \%$ & $91.92 \%$ \\
\hline Temerário & 551 & $95.64 \%$ & $96.37 \%$ & $94.92 \%$ & $90.56 \%$ \\
\hline \multicolumn{1}{c}{ Total } & $\mathbf{5 . 0 0 0}$ & $\mathbf{9 4 . 2 0 \%}$ & $\mathbf{9 4 . 5 4 \%}$ & $\mathbf{9 3 . 7 0 \%}$ & $\mathbf{8 9 . 4 0 \%}$ \\
\hline \multicolumn{7}{r}{ Média } & 94.37 & 94.61 & 93.84 & 89.53 \\
\hline \multicolumn{7}{r}{ Mínimo } & 76.63 & 85.98 & 78.13 & 75.46 \\
\hline Méximo & 97.83 & 96.39 & 96.55 & 93.14 \\
\hline
\end{tabular}

onde, $n$ é a quantidade de amostra que representa determinado perfil de personalidade.

Tabela 4. Resultados da classificação dos perfis de personalidade com 10.000 amostras para treinamento e 4 arquiteturas de RNA

\begin{tabular}{lccccc}
\hline \multicolumn{1}{c}{ Perfis } & $n$ & $\begin{array}{c}\text { 1 camada oculta } \\
\text { com 5 neurônios }\end{array}$ & $\begin{array}{c}\text { 1 camada oculta } \\
\text { com 20 neurônios }\end{array}$ & $\begin{array}{c}\text { 2 camadas ocultas } \\
\text { com 5 neurônios }\end{array}$ & $\begin{array}{c}\text { 2 camadas ocultas } \\
\text { com 20 neurônios }\end{array}$ \\
\hline Afetivo & 1.098 & $96.90 \%$ & $96.72 \%$ & $97.18 \%$ & $93.72 \%$ \\
\hline Astucioso & 1.057 & $97.45 \%$ & $97.26 \%$ & $97.45 \%$ & $93.95 \%$ \\
\hline Dócil & 1.128 & $97.25 \%$ & $97.87 \%$ & $87.15 \%$ & $94.59 \%$ \\
\hline Eremita & 1.087 & $97.15 \%$ & $97.33 \%$ & $96.23 \%$ & $96.04 \%$ \\
\hline Excessivo & 1.083 & $97.14 \%$ & $96.68 \%$ & $96.68 \%$ & $96.31 \%$ \\
\hline Flexível & 1.223 & $88.39 \%$ & $97.47 \%$ & $86.92 \%$ & $94.77 \%$ \\
\hline Meticuloso & 1.113 & $98.56 \%$ & $98.11 \%$ & $85.62 \%$ & $95.78 \%$ \\
\hline Teatral & 1.095 & $97.08 \%$ & $97.35 \%$ & $96.71 \%$ & $94.89 \%$ \\
\hline Temerário & 1.116 & $97.04 \%$ & 96.68 & $95.97 \%$ & $95.43 \%$ \\
\hline \multicolumn{7}{c}{ Total } & $\mathbf{1 0 . 0 0 0}$ & $\mathbf{9 6 . 2 3 \%}$ & $\mathbf{9 7 . 2 8 \%}$ & $\mathbf{9 3 . 1 9 \%}$ & $\mathbf{9 5 . 0 5 \%}$ \\
\hline Média & 96.32 & 97.27 & 93.32 & 95.05 \\
\hline Mínimo & 88.39 & 96.68 & 85.62 & 93.72 \\
\hline Máximo & 98.56 & 98.11 & 97.45 & 96.31 \\
\hline
\end{tabular}

onde, $n$ é a quantidade de amostra que representa determinado perfil de personalidade.

Os resultados apresentados na Tabela 4, em termos de classificação geral são 96,23\%, 97,28\%, 93,19\% e 95,05\% de precisão, respectivamente nas arquiteturas definidas. Porém, ao analisar cada perfil de personalidade, mesmo com uma precisão geral relativamente considerável, os perfis "Flexível", "Dócil" e "Meticuloso" não obtiverem precisão igual ou superior a 90\% nas arquiteturas que utilizaram 2 camadas ocultas.

Ao aumentar o número de exemplos fornecidos a RNA, todos os perfis de personalidade foram classificados adequadamente. Assim, define-se esta a melhor base de treinamento (10.000 amostras). Além disso, a arquitetura ótima da RNA é definida por 1 camada de entrada composta por 62 neurônios, 1 camada oculta com 20 neurônios e, 9 neurônios na camada de saída. Através dessa análise experimental, a classificação dos perfis de personalidade atingiu 97,28\% de precisão no reconhecimento de todos os perfis de personalidade. 
VI Congresso Brasileiro de Informática na Educação (CBIE 2017)

Anais do XXVIII Simpósio Brasileiro de Informática na Educação (SBIE 2017)

\subsection{Aplicação do questionário}

O questionário desenvolvido foi aprovado pelo Conselho de Ética da Universidade Federal de Uberlândia. Sendo assim, foi aplicado para 172 alunos dos cursos de graduação em Física, Engenharia Aeronáutica, Administração, Gestão da Informação, Sistemas de Informação e pós-graduação em Ciência da Computação, da mesma instituição de ensino. As respostas obtidas foram informadas a RNA, treinada e validada com a melhor arquitetura e base de treinamento. Os resultados da classificação, com dados reais de estudantes, são exibidos na Figura 2.

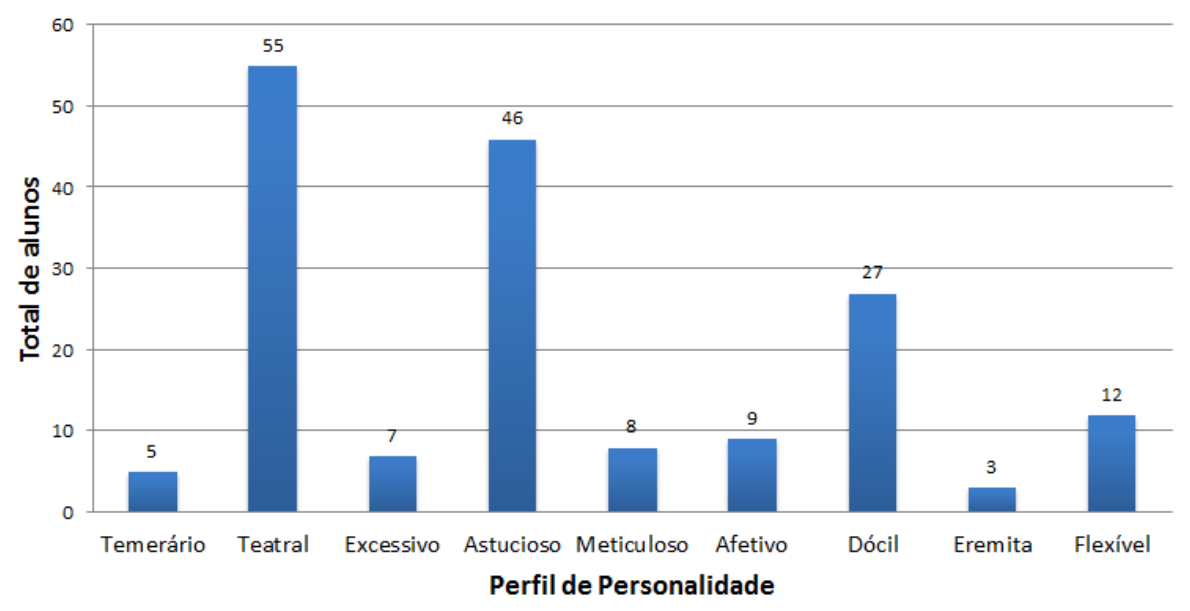

Figura 2. Classificação Perfis de Personalidade com dados reais.

Ao observar a Figura 2, verifica-se a diversidade entre os estudantes. Desse modo, cada estudante deverá ser motivado em função de seu perfil de personalidade. Além disso, note que, a RNA classificou adequadamente 12 alunos com o perfil Flexível, que é considerado um raro perfil de personalidade.

Dentre os alunos que responderam o questionário, 33 alunos foram informados da classificação e descrição de seu perfil de personalidade. Todavia, esses alunos concordaram e identificaram totalmente com as definições descritas por [Chabot 2005].

\subsection{Determinação das Estratégias Pedagógicas utilizando Árvore de Decisão}

Com intuito de selecionar um conjunto ótimo de recomendação pedagógica, inicialmente desenvolveu-se um conjunto composto por 42 regras (estratégias pedagógicas), de acordo com a pedagogia emocional proposta por [Chabot 2005]. Para isto, associou-se cada "conselho ao educador", presente na teoria, com as seis emoções básicas e a dinâmica emocional de cada perfil de personalidade.

Uma Árvore de Decisão (AD) Best First Tree [Shi 2007] funciona basicamente como preditores de regras. Assim, essa técnica de aprendizagem foi desenvolvida para extrair a regra (estratégia pedagógica) que apresenta maior ganho de informação (melhor atributo da árvore), comparada ao conjunto original de determinada classe (perfil). Como resultados, a AD minimizou o conjunto inicial (42 regras) para 15 melhores regras pedagógicas (RP), detalhado na Tabela 5, responsáveis por conduzir cada perfil de personalidade para o estado afetivo ideal ao aprendizado. 
VI Congresso Brasileiro de Informática na Educação (CBIE 2017)

Anais do XXVIII Simpósio Brasileiro de Informática na Educação (SBIE 2017)

Tabela 5. Conjunto ótimo de estratégias pedagógicas definido pela AD

\begin{tabular}{|l|l|l|}
\hline RP & \multicolumn{1}{|c|}{ SE } & \multicolumn{1}{c|}{ ENTÃo } \\
\hline R1 & (perfil=Afetivo) & Todas as emoções: Fazê-lo sentir que tem valor aos seus olhos. \\
\hline R2 & (perfil=Astucioso) & [emoção=(alegria ou tristeza ou raiva)]: Interrogá-lo sobre seus comportamentos e reações. \\
\hline R3 & (perfil=Astucioso) & [emoção=(desgosto ou tristeza ou medo)]: Convidá-lo a se expressar diretamente. \\
\hline R4 & (perfil=Excessivo) & [emoção=(desgosto)]: Relativizar o conteúdo. \\
\hline R5 & (perfil= Excessivo) & Demais emoções: Estimular o estudante pela novidade e, garantir segurança. \\
\hline R6 & (perfil=Eremita) & [emoção=(alegria)]: Propor ao estudante atividades rotineiras. \\
\hline R7 & (perfil=Eremita) & Demais emoções: Abordá-lo por meio de seus interesses. \\
\hline R8 & (perfil=Dócil) & [emoção=(tristeza)]: Abordá-lo de modo caloroso. \\
\hline R9 & (perfil=Dócil) & [emoção=(surpresa ou raiva ou alegria ou desgosto ou,medo)] Ajudá-lo a tomar iniciativa. \\
\hline R10 & (perfil=Teatral) & Em todas as emoções: Evitar ameaçá-lo pela punição. \\
\hline R11 & (perfil=Temerário) & [emoção=(alegria ou medo)] : Estimulá-lo com novidades. \\
\hline R12 & (perfil=Temerário) & [emoção=(desgosto)]: Lançar-lhe desafios. \\
\hline R13 & (perfil=Temerário) & [emoção=(surpresa, raiva ou tristeza)]: Evitar provocá-lo. \\
\hline R14 & (perfil=Flexível) & Variar e testar os ângulos à partir dos quais abordá-lo (novidade, punição e reforço). \\
\hline R15 & perfil=Meticuloso) & Estimular sua confiança e sua criatividade. \\
\hline
\end{tabular}

Ao observar a Tabela 5, alguns perfis mostram RP divididas por determinadas emoções. Isso se deve, pelo fato das regras pedagógicas terem sido formadas observando os aspectos emocionais e necessidades predominantes de cada perfil, uma vez que, cada perfil têm necessidades predominantes diferentes de outro.

Este conjunto ótimo também foi informado aos 33 alunos, da mesma forma da descrição do perfil de personalidade. No entanto, as regras selecionadas foram informadas de acordo com a classificação de cada perfil. Assim, $80 \%$ do alunos concordaram totalmente com as estratégias pedagógicas expostas a ele, $20 \%$ concordou parcialmente e, nenhum aluno/perfil discordou das regras pedagógicas estipuladas.

\section{Considerações Finais e Trabalhos Futuros}

Neste trabalho propôs a modelagem afetiva do estudante baseada em emoções e perfis de personalidade a fim de desenvolver estratégias pedagógicas personalizadas as características individuais do estudante. Para tanto, efetuou-se a validação computacional dos principais módulos que compõem a abordagem proposta.

Os resultados obtidos da classificação do perfis de personalidade foram considerados precisos para integração em Ambientes Virtuais de Aprendizagem, assim como a otimização das estratégias pedagógicas adequadas a cada perfil. Como trabalhos futuros, pretende-se verificar a eficiência das estratégias pedagógicas definidas nesse trabalho, por meio da atuação de um agente pedagógico e, além disso acompanhar a evolução emocional do estudante, ou seja, verificar a permanência ou a aproximação do estudante no estado afetivo ideal à aprendizagem após receber estímulos/motivação adequados as suas características.

Ainda como trabalho futuro, pretende-se utilizar das informações armazenadas no Modelo do Estudante no processo colaborativo. Neste sentido, poderá formar grupos de estudantes do mesmo perfil de personalidade e, observar como esses perfis reagem na execução de tarefas em grupo, bem como a observação das emoções. Além disso, o contrário também poderá ser observado, isto é, a observação da formação de grupos de estudantes com perfis heterogêneos. 
VI Congresso Brasileiro de Informática na Educação (CBIE 2017)

Anais do XXVIII Simpósio Brasileiro de Informática na Educação (SBIE 2017)

\section{Referências}

Chabot, D. (2005). Pedagogia emocional-sentir para aprender. Sa Editora.

Chen, G. and Lee, M. (2012). Detecting emotion model in e-learning system. Proceedings of the 2012 International Conference on Machine Learning and Cybernetics, pages $40-54$.

Chrysafiadi, K. and Virvou, M. (2015). Advances in personalized web-based education.

Cloninger, C. R., Svrakic, D. M., and Przybeck, T. R. (1993). A psychobiological model of temperament and character. Archives of general psychiatry, 50(12):975-990.

Dantas, A. C., de Melo, S., Moura, F., and Fernandes, M. (2015). Reconhecimento dinâmico de emoções através de expressões faciais utilizando árvore de decisão. XXVI Simpósio Brasileiro de Informática na Educação (SBIE 2015), page 1102.

Fausett, L. (1994). Fundamentals of Neural Networks - Architectures, Algorithms, and Applications. Prentice-Hall, New York, USA, 1st edition.

Frozza, R., da Silva, A. A. K., Schreiber, J. N. C., Lux, B., Molz, K. W., Kipper, L. M., Borin, M. P., de Carvalho, A. B., Baierle, J. L., and Sampaio, L. (2011). Agentes pedagógicos emocionais atuando em um ambiente virtual de aprendizagem. RENOTE, 9(1).

Giraffa, L. M. M. and Viccari, R. M. (1999). Estratégias de ensino em sistemas tutores inteligentes modelados através da tecnologia de agentes. Revista Brasileira de Informática na Educação, 5(1):9-18.

Izard, C. E. (1984). Emotion-cognition relationships and human development. Emotions, cognition, and behavior, pages 17-37.

Jaques, P. and Vicari, R. (2005). Pat: um agente pedagógico animado para interagir efetivamente com o aluno. RENOTE, 3(1).

John, O. P. and Srivastava, S. (1999). The big five trait taxonomy: History, measurement, and theoretical perspectives. Handbook of personality: Theory and research, 2(1999):102-138.

Kort, B., Reilly, R., and Picard, R. W. (2001). An affective model of interplay between emotions and learning - reengineering educational pedagogy-building a learning companion. IEEE Computer Society, pages 0043-0043.

Melo, S. L. (2016). Modelo do estudante baseado em emoções e perfis de personalidade para recomendação de estratégias pedagógicas personalizadas. Master's thesis, Universidade Federal de Uberlândia.

Myers, I. B., McCaulley, M. H., and Most, R. (1985). Manual, a guide to the development and use of the Myers-Briggs type indicator. Consulting Psychologists Press.

Rodrigues, L. M. L. and Carvalho, M. (2005). Sti-i: Sistemas tutoriais inteligentes que integram cognição, emoção e motivação. Revista Brasileira de Informática na Educação, 13(1):20-34.

Shi, H. (2007). Best-first decision tree learning. PhD thesis, Citeseer.

Stipek, D. J. (2002). Motivation to learn: Integrating theory and practice. Allyn \& Bacon. 